\title{
Real-Time Assessment of the Burden on the Community of Informal Caregivers. A Pilot Study
}

\author{
Anna Pettini ${ }^{1,2}$ (iD \\ Received: 11 February 2020 / Accepted: 5 October 2020 / Published online: 16 October 2020 \\ (C) The Author(s) 2020
}

\begin{abstract}
Good mental health is a critical part of individual well-being, and one of the cornerstones of community well-being. This paper focuses on the community of parents of young psychiatric patients, whose well-being loss is significant because of the enormous burden of suffering that results from their children's illness. This burden is seldom considered by the ordinary calculations of the costs of mental illness. We suggest that digital daily diaries (DDDs) with instant reporting can become a powerful tool to estimate the intangible costs of mental illness, namely the loss of well-being suffered by the community of informal caregivers. A pilot study was carried out to test the validity of the digital tool. The results of instant reports provide accurate information and are consistent with those obtained through other traditional survey methods. The digital data-gathering tool can be extended to design an affordable, prompt, and cost-effective possible solution for policy-oriented interventions. Besides, this digital tool can easily be extended to collect real-time big data and to use them in conjunction with Artificial Intelligence (AI) to give professionals a powerful tool to face a relevant community issue.
\end{abstract}

Keywords Community well-being · Intangible costs $\cdot$ Mental health · Informal caregivers · Artificial intelligence $\cdot$ Instant daily report $\cdot$ Digital health

JEL Classification $\mathrm{I} 31 \cdot \mathrm{I} 10 \cdot \mathrm{O} 33 \cdot \mathrm{H} 51$

Anna Pettini

anna.pettini@unifi.it

1 Department of Economics and Management, University of Florence, Florence, Italy

2 DataLifeLab, University of Florence, Florence, Italy 


\section{Introduction}

In February 2020, the FDA officially launched a new digital health program, encouraging the development of mobile medical apps (MMA) to provide citizens and health care professionals with valuable health information (FDA 2020). This paper suggests that digital health tools can be useful to measure the intangible burden of disease that mental illness causes on the community of families of psychiatric patients and, to this purpose, we test the validity of a digital monitoring app. Good mental health is a critical part of individual well-being, the foundation for happy, fulfilled, productive lives, and one of the cornerstones of community well-being (Musikanski et al. 2020). However, about 380 million people worldwide have severe mental disorders (Ritchie and Roser 2020; Vigo et al. 2016; Whiteford et al. 2013; WHO 2019), and related costs are huge. The Lancet alerts that mental ill-health might cost the global economy up to 16 trillion dollars by 2030 (Patel et al. 2018). The OECD calculated that the cost of mental illness in the EU exceeded 4\% of GDP in 2015 (OECD/European Union 2018), and some research estimated that mental illness accounts for one-third of all costs of noncommunicable diseases (Bloom et al. 2016).

These figures include only direct and indirect costs, but not intangible costs. Direct costs cover health care, medicines, and therapies. Indirect costs concern the labour market, where mental illness leads to lower employment rates and reduced productivity, absence of work, presenteeism (the loss in productivity even when at work), and expenditures on social security programs (OECD 2014). A full economic evaluation of mental ill-health should encompass the well-being costs (Lynch and Dickerson 2018; Goodrich et al. 2012; OECD 2014), i.e. the intangible costs. Intangible costs take account of the reduced well-being, of both patients and the community of informal caregivers, caused by emotional distress, pain, and other forms of suffering. They are the most difficult component to accurately quantify and, for this reason, are often excluded from the calculation of the total costs of mental illness (Doran and Kinchin 2017). The introduction of a digital tool for the measurement of intangible costs offers the possibility to (1) overcome the difficulty of measurement and (2) have an instrument that, in perspective, can improve the efficiency and cost-effectiveness of care (WHO 2020; Krol et al. 2015). The Lancet stresses that when it comes to mental health, the effectiveness and efficiency of any intervention requires a partnership between all actors involved, i.e. family groups, mental health professionals, suppliers, professional associations (Patel et al. 2018; Vigo et al. 2019).

This study focuses on the community of parents of psychiatric patients, as they carry the heaviest burden in terms of time, care, emotional burden and change in the quality of life (Pinquart and Sörensen 2003; Viana et al. 2013). Caregiver parents are likely to have high levels of stress and feelings of guilt (Daltro et al. 2016; Murphy et al. 2007; Dore and Romans 2001). The suffering of parents can lead to further physical and psychological illnesses (Weatherly et al. 2017), while the physical and psychological balance of parents helps to minimize the social burden of the disease, and is crucial to the children's chances of recovery (Piotrowska et al. 2017; Östman and Hansson 2004). Many different approaches define what the burden is (Bastawrous 2013). The caregiver's burden may be subjective or objective (Molebatsi et al. 2017; Tessler and Gamache 2000). The subjective burden refers to the psychological effects of care activity on caregivers, and it depends on the caregiver's material and internal resources 
(Litzelman et al. 2017). The objective burden refers to the effects of care on daily life, such as altered habits, changing work time, leisure time, and holidays that no longer have the quality of leisure time. While living with mentally ill children, caregivers endure psychological, emotional, social, and economic challenges (Ampalam et al. 2012; Ambikile and Outwater 2012; Kaas et al. 2003). For this paper, the terms: (1) intangible costs, (2) loss of well-being of the community of caregivers, and (3) caregivers' burden, should be taken as synonymous.

\section{Methodology}

The goal of this pilot study was to test a digital daily diary (DDD) to evaluate the intangible costs suffered by informal caregivers of young psychiatric patients. The hypothesis underlying the pilot study was that intangible costs could be captured by assessing the differences between the perceived well-being of caregivers and that of parents of healthy children (Hoefman et al. 2013). Throughout the text, the term 'caregiver' is used to address the parents of mentally ill adolescents and interchangeably with the more accurate 'informal caregiver', which distinguishes family and friend caregivers from professional caregivers. We compared the data collected with the digital tool with data obtained through other traditional survey methods. Using a small sample of caregivers and a control group, we built a survey through three different stages of data gathering in chronological order: (1) an ex-ante questionnaire and an indepth interview; (2) an organized flow of timed questionnaires received by smartphone for one week; (3) a final in-depth interview accompanied by the administration of an additional psychometric questionnaire. Ex-ante in-depth interviews included a questionnaire aimed at generating their profiles. The collected answers automatically created part of the timed questionnaire. The ex-ante interviews included a subjective well-being questionnaire, concerning overall life satisfaction, work, family, health, environment, relationships, and leisure (ISTAT 2014). In addition to the questions about self-perceived well-being, the ex-ante questionnaire administered another sequence of questions focusing on the daily routine of the family.

To gather data by a DDD, an open-source tool for instant reporting was developed. Instant data collection was carried out through a highly scalable smartphone application prototype for individual monitoring. Data collection ended with an in-depth interview, accompanied by the administration of the Caregiver Burden Inventory (CBI) questionnaire (Novak and Guest 1989). Data from caregivers' instant reports was compared to those obtained by the CBI questionnaire, data from the control group with national data, and data from the DDDs with those gathered by ex-ante and ex-post in-depth interviews. In what follows, the various steps are described.

\section{The Sample}

Caregivers of young psychiatric patients were chosen for the study to facilitate their evaluation of the differences between life before and life after the onset of the disease and to avoid distortions caused by the process of adaptation (Diener et al. 2009). The sample used for the pilot project was a group of five parents of adolescents with 
different psychiatric diagnoses (bipolar affective disorder, schizoaffective disorders that are highly psychotic and borderline, manic-obsessive disorders) from the Centre for Mental Health in Florence, Italy, a part of the National Health Service (NHS). In all cases, the illness manifested during adolescence in association with other pathologies (alcoholism and anorexia) or minor disorders (dyscalculia and dyslexia). Within the group of caregivers, we interviewed three fathers and two mothers and asked them to complete the DDD. In four cases, the mentally ill child was at home, while in the last case the child was in charge of a health care facility. Before the start of the survey, a pre-test was performed with a caregiver mother whose mentally ill adolescent daughter lived at home. The interview and the preliminary questionnaire were designed to test the application usage, possible technical problems, and formulation errors. We used the data obtained in the pre-test in the final analysis, since only minor improvements and no relevant changes occurred from the pre-test to the pilot.

Flow sampling helped to define the control group, which was composed of five parents of adolescents in good health with similar socio-economic and demographic characteristics. To avoid overestimation of the differences between the caregivers and the control group, the latter was chosen within large families with a high family burden (defined as three or four dependent adolescents for each parent interviewed). For the control group, we interviewed four mothers and one father.

\section{Ex-Ante Contextualized in-Depth Interviews}

The duration of the first meeting was different for the two groups: for the group of caregivers, the average duration was $50 \mathrm{~min}$, and for the control group, the duration was $30 \mathrm{~min}$. This difference in time was partly due to the longer length of the caregivers' responses. Five out of six interviews with the control group were carried out at their family homes to facilitate the conversation in an informal setting. Two out of the six caregivers preferred to be interviewed in a public place because the conversation could alter the tranquillity of their children. The meeting process was the same for both groups. First, the research project was explained to the participants, and the in-depth interview administered. Afterwards, the application on the mobile devices of the participants was installed and activated the bot system for the reception of the DDD. The biographical interviews followed a life-narration model, with low directivity and standardization. Among the empirical dimensions, we considered contextual dimensions, such as specific aspects of life (work, family, and informal networks), dimensions connected to experience (motivations and opinions), sentimental aspects (feelings and emotions), and specific aspects of the biography of responders (age, adolescence, and education). Starting with self-narration, the caregivers described their experience with the disease of their adolescent child and the related social experience.

\section{Digital Daily Diaries}

The development of the DDD took its cue from the surveys conducted by the Italian National Statistical Office (ISTAT), especially the Use of Time Survey and the Aspects of Daily Life Survey. The Use of Time Survey is a tool used by ISTAT to observe how 
Table 1 Questionnaire for the digital daily diary

Digital Daily Diary

With automatic tracking of time and place

At fixed intervals, five times a day

Question added on

the evening

questionnaire only

\begin{tabular}{|c|c|c|c|c|}
\hline Type of & question & $\begin{array}{l}\text { Multiple } \\
\text { answers }\end{array}$ & 10-points Likert scale & Open question \\
\hline Open & question & & & \\
\hline Questions & $\begin{array}{l}\text { "Have you been alone or with } \\
\text { others?" }\end{array}$ & $\begin{array}{l}\text { "How well did } \\
\text { you feel in } \\
\text { this period } \\
\text { of the day?" } \\
\text { "How hard } \\
\text { was this } \\
\text { interval of } \\
\text { time?" }\end{array}$ & $\begin{array}{l}\text { "During this time, did } \\
\text { you met other people } \\
\text { you consider } \\
\text { important in your } \\
\text { life?" } \\
\text { "What have you done } \\
\text { since the last time } \\
\text { you answered the } \\
\text { questionnaire?" }\end{array}$ & $\begin{array}{l}\text { "What/who would } \\
\text { you have needed } \\
\text { to improve the } \\
\text { quality of this } \\
\text { day?" }\end{array}$ \\
\hline Answers & $\begin{array}{l}\text { choose Alone, Mother. Father. } \\
\text { Spouse/partner, Child with } \\
\text { psychiatric pathology, Other } \\
\text { Son, Brother/sister, Other } \\
\text { cohabiting family members, } \\
\text { colleagues, others.* }\end{array}$ & $\begin{array}{c}0=\text { not at all to } \\
10=\text { all }\end{array}$ & Free & Free \\
\hline
\end{tabular}

*The list was automatically adjusted with names provided during the ex-ante questionnaire

responders organize their daily lives and interact with the routines of the other family members. The compilation of a DDD shows how each caregiver distributes the daily activities over the $24 \mathrm{~h}$. The DDD was administered via a notification system for smartphones (see Appendix), which sent questions at predetermined intervals. Some questions of the DDD were personalized according to the answers given on the ex-ante questionnaires. For instance, daily questions already included names and some information about family members. DDDs registered also the level of subjective well-being of the participants on a ten-point Likert scale five times a day. In the evening, the questionnaire recorded the overall assessment of well-being during the day (here called daily well-being) as recreated by the participants before going to bed. (Table 1).

\section{Ex-Post Questionnaire}

The final questionnaire posed the last questions to the participants of the pilot study. In the course of the last meeting, caregivers were shown their daily reports to share and check our findings with them. At the end of the trial week, the Caregiver Burden Inventory (Novak and Guest 1989) was administered to the caregivers' group. It consists of a scale of 24 items with a $0-4$ score on five dimensions. The dimensions identify five different types of burden: (1) time required for assistance, (2) developmental burden, (3) physical burden, (4) social burden and (5) emotional burden. 


\section{Findings and Analysis of In-Depth Interviews}

Table 2 briefly outlines the results of the qualitative ex-ante in-depth interviews.

Table 2 shows that informal caretakers generally fared worse off than the control group. Our results are consistent with findings from other research (Ampalam et al. 2012; Ambikile and Outwater 2012; Awad and Voruganti 2008).

\section{Findings and Analysis of the Instant Report from DDDs}

Table 3 presents the average values of the well-being of the caregivers and the control group during the reference week and their difference.

Table 2 Comparative results of the in-depth interviews

Type of activity Informal caregiver
Control group

(parents with a large family: 3 or 4 dependent children)

\begin{tabular}{|c|c|c|}
\hline Leisure & $\begin{array}{l}\text { - Scarce, even on weekends. } \\
\text { - Not relaxing. } \\
\text { - Difficult to organise. } \\
\text { - Few friends. } \\
\text { - Solitude is preferred to avoid } \\
\text { comparison with other families. }\end{array}$ & $\begin{array}{l}\text { - Have time for themselves and hobbies, for } \\
\text { family, and volunteering. } \\
\text { - Mainly enjoyed over weekends. } \\
\text { - Usually, meet friends. }\end{array}$ \\
\hline Family work & $\begin{array}{l}\text { - Difficulties in conciliating family work } \\
\text { with paid work. }\end{array}$ & $\begin{array}{l}\text { - Difficulties in conciliating family work with } \\
\text { paid work (especially for women). } \\
\text { - The whole week is scheduled with } \\
\text { deadlines and a fast pace. }\end{array}$ \\
\hline • & & \\
\hline $\begin{array}{l}\text { Care of the } \\
\text { patient }\end{array}$ & $\begin{array}{l}\text { - Continuous and heavy. } \\
\text { - Reduced when the child is in care } \\
\text { facilities, but still existing. } \\
\text { - Heavily concentrated on the emotional } \\
\text { support to the child. }\end{array}$ & Not applicable \\
\hline Paid work & $\begin{array}{l}\text { - Considered as a break from family. } \\
\text { - Left, in some cases, to take care of their } \\
\text { child. }\end{array}$ & - Tiring but also satisfying. \\
\hline Rest & $\begin{array}{l}\text { - Very little. } \\
\text { - Even when the child is away, the worry } \\
\text { persists. }\end{array}$ & - There are breaks from daily routines. \\
\hline Self-care & $\begin{array}{l}\text { - Insufficient time for individual care. } \\
\text { - Mental and physical distress affect the } \\
\text { caregiver's health. } \\
\text { - At times, some caregivers do not have } \\
\text { healthy lifestyles. }\end{array}$ & - Find time for themselves. \\
\hline $\begin{array}{l}\text { Professional } \\
\text { support } \\
\text { needed }\end{array}$ & $\begin{array}{l}\text { - Psychological support and home } \\
\text { assistance when the child is at home. } \\
\text { - A professional to act as a guide through } \\
\text { territorial services and facilities. } \\
\text { - Information courses about the disease } \\
\text { and group meetings. }\end{array}$ & Not applicable \\
\hline
\end{tabular}


Table 3 Well-being and daily well-being in the caregivers' group and the control group (average values)

\begin{tabular}{llll}
\hline & Caregivers & Control group & Loss of well-being \\
\hline Well-being & 5.8 & 7.7 & $-33 \%$ \\
Daily well-being & 5.5 & 6.9 & $-25 \%$ \\
\hline
\end{tabular}

The loss of well-being measures the burden of disease on caregivers, i.e. the intangible cost of mental illness suffered by the community of caregivers. Table 3 indicates that the differences between the well-being of caregivers and parents of healthy children are high. Interestingly enough, the loss of caregivers' well-being recorded during the day $(-33 \%)$ is greater than that registered in the evening $(-25 \%)$.

Figure 1 displays the absolute differences of well-being between caregiver and the control group, by time range and day of the week.

Figure 1 shows that Friday evening is the moment with the largest difference between the caregivers and the control group, arguably because the latter can take a break from work. Conversely, caregivers may not perceive the weekend as a break from the rest of the week, maybe because their weekends are more tiring in terms of physical and psychological energy required for caregiving.

Table 4 presents the levels of subjective well-being (SWB) measured by daily activities for caregivers, the control group and the Italian population (ISTAT data), and the percentage differences of SWB between the two groups of the sample of this pilot. To facilitate the reading of the results of the open questions, we reclassified activities into categories taken from the report on the Use of Time Survey of ISTAT.

Table 4 shows a high loss of well-being for caregivers across all the activities, except for time at work. Caregivers seem to perceive higher well-being when they are at work, while they feel worse in leisure hours. Being a worker and not a caregiver appears to be, for informal caregivers, a relief, and an opportunity to take a break from daily distress. Comparing the data collected from the control group with the data from the

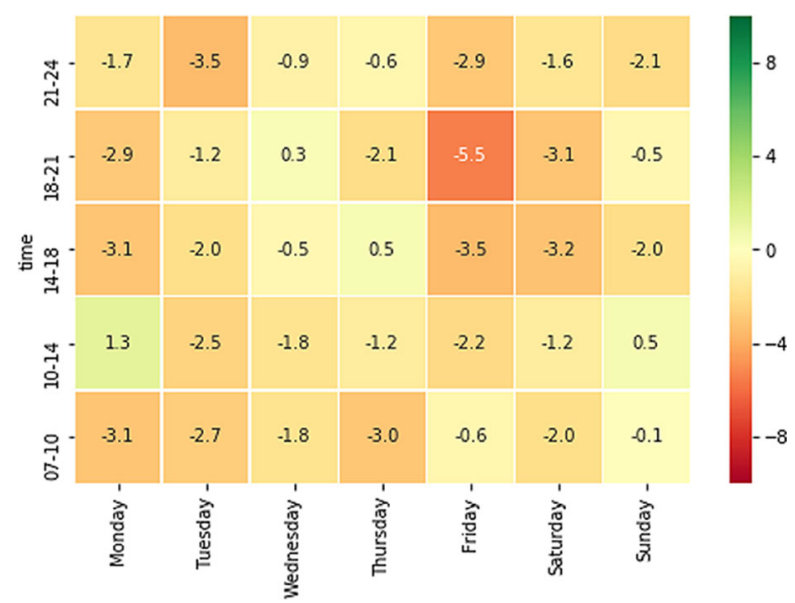

Fig. 1 The difference between the caregivers and the control group in terms of well-being perceived during the week (absolute values) 
Table 4 Subjective well-being /Loss of well-being by type of activity (average values)

\begin{tabular}{lllll}
\hline SWB & Caregivers & Control group & $\begin{array}{l}\text { National } \\
\text { data (ISTAT) }\end{array}$ & Loss of well-being \\
\hline Leisure & 6.9 & 8.4 & 8.4 & $-21,7 \%$ \\
Family work & 5.0 & 7.3 & 7.2 & $-46 \%$ \\
Care of the patient & 4.9 & Not applicable & Not applicable & Not applicable \\
Paid work & 6.3 & 7.1 & 6.7 & $-12,6 \%$ \\
Rest & 6.4 & 8.9 & Not applicable & $-39 \%$ \\
Individual care & 6.6 & 8.6 & 8.0 & $-30,3 \%$ \\
\hline
\end{tabular}

ISTAT sample (columns 3 and 4 of Table 4), we observe that SWB of our control group is very close to that calculated on national data.

The following three tables present some additional results. Table 5 presents the perceived loss of well-being by daily activities and the differences between the two groups. Table 6 presents the values of well-being perceived by mothers and fathers within each family. Table 7 presents the well-being by the type of socialization.

Table 5 shows that the loss of well-being perceived by the two groups differ, but much less than in the case of the SWB measurement. The adaptation processes (Diener et al. 2009) may explain this difference between the two measures.

Table 6 shows that the well-being of caregiver mothers is lower than that of caregiver fathers. Within the control group, differences are smaller.

Table 7 demonstrates that the level of well-being also varies according to the kind of companionship (family, colleagues, or no company at all). Caregivers have a higher level of well-being when they are with colleagues, possibly because they share time with them when at work, which is consistent with results from Table 4. Conversely, caregivers enjoy the time spent with family and alone much less than the control group.

\section{Findings and Analysis of the Caregiver Burden Inventory}

Table 8 shows the average value of each Caregiver Burden Inventory entry. The highest values were recorded on the dimensions of developmental and physical burdens. The developmental burden refers to the caregiver's feeling of being excluded

Table 5 Perceived loss of well-being and differences (average values)

\begin{tabular}{llll}
\hline Loss of well-being perceived & Caregivers & Control group & Difference \\
\hline Leisure & 5.3 & 4.5 & $+15 \%$ \\
Family work & 6.7 & 5.5 & $+17 \%$ \\
Care of the patient & 6.9 & Not applicable & - \\
Paid work & 5.8 & 5.6 & $+3 \%$ \\
Rest & 4.0 & 3.4 & $+15 \%$ \\
Individual care & 5.0 & Not applicable & - \\
\hline
\end{tabular}


Table 6 Well-being and daily well-being within the family (average values)

\begin{tabular}{llll}
\hline & Family role & Well-being & Daily well-being \\
\hline Caregivers & Mother & 5.2 & 4.6 \\
& Father & 6.8 & 6.8 \\
Control group & Mother & 7.7 & 6.8 \\
& Father & 7.6 & 7.5 \\
\hline
\end{tabular}

from the expectations and opportunities of their equals; the physical burden describes a sense of chronic fatigue and physical health problems.

The physical burden dimension shows a low variation, indicating that the physical effort affects all caregivers. The greatest variance recorded is for the social burden, meaning that the perception of a conflict with other family members varies a lot among caregivers.

To analyse the Caregiver Burden Inventory (CBI) and the findings of the experiment through the DDDs, we calculated the correlational between well-being, daily wellbeing, and the heaviest dimensions of the burden, namely the evolutionary burden and the physical burden.

Table 9 shows that the well-being and burden of disease are highly negatively correlated. This result confirms that the loss of well-being measure, obtained from data by DDDs, can be an excellent predictor of the burden of disease borne by caregivers of psychiatric young patients.

\section{Discussion}

The results of the pilot study indicate that DDD is a useful, tool to measure the loss of well-being suffered by the caregiver community. The results obtained by DDDs are consistent with those obtained by other traditional data collection methods, such as in-depth interviews, measurements obtained by using official statistical data, and a psychometric scale. The DDD gives results in real-time, thus overcoming the latency associated with the other methods of data collection. The DDD offers the possibility to gain a detailed view of the most common difficulties encountered by the caregivers' community, to identify the most difficult daily moments, and to quantify the loss of well-being experienced by caregivers. Analysis of the DDD revealed that the mental illness of a caregiver's adolescent child impacts on the whole life of caregivers, from work to socialization. The

Table 7 Well-being by context (average values)

\begin{tabular}{lllll}
\hline & Type of socialization & Caregiver & Control & Difference \\
\hline Well-being with & Family members & 5.9 & 7.8 & $-32 \%$ \\
Well-being with & Work colleagues & 6.5 & 6.9 & $-6 \%$ \\
Well-being when & Alone & 5.4 & 7.9 & $-46 \%$ \\
\hline
\end{tabular}


Table 8 Caregiver burden inventory questionnaire (score $0-4$ )

\begin{tabular}{lll}
\hline Types of burden & Average value & $\begin{array}{l}\text { Variance } \\
\text { (among caregivers) }\end{array}$ \\
\hline Time & 1.28 & 1.03 \\
Developmental & 2.39 & 1.18 \\
Physical & 2.46 & 0.59 \\
Social & 1.64 & 2.92 \\
Emotional & 1.3 & 0.7 \\
\hline
\end{tabular}

comparison between the caregivers and the control group shows clear differences in the use of time during the week, accessibility to activities, and levels of wellbeing. Table 3 shows that the loss of caregivers' well-being assessed during the day is greater than that registered in the evening (daily well-being). It is not clear whether the perceived well-being during the day is more accurate than the one recreated at the end of the day, or the opposite is true. At the end of the trial week the caregivers, looking at their daily reports, reconstructed the good and the bad moments and attributed greater accuracy to the level of perceived well-being during the day. Ludwigs et al. (2019) show that the assessments of one's happiness reconstructed at the end of one day or the day after do not significantly different. In the case of this pilot project, the temporal moments and questions are not directly comparable with the above-mentioned study. However, the differences shown in Table 3 deserve to be explored further.

\section{Limitations}

A major limitation of the pilot study is the size of the sample. Since the control group consists of large families and caregivers' families in the sample have a maximum of two children, the differences in well-being recorded by the pilot study could vary had families of the same size been compared.

\section{Recommendations}

To date, neither digital tools nor artificial intelligence has been used to estimate the intangible costs of mental illness.. When the emotional burden suffered by

Table 9 Correlations between well-being and daily well-being with the developmental burden (items 6-10) and physical burden (items 20-24) from the Caregiver Burden Inventory (CBI)

\begin{tabular}{lll}
\hline Sections of CBI & Well-being & Daily well-being \\
\hline Developmental burden & -0.92 & -0.93 \\
Physical burden & -0.7 & -0.81 \\
\hline
\end{tabular}


caregivers cannot be monetized or reimbursed, this study indicates that additional services identified by DDDs might partly compensate the community of caregivers. This pilot study also indicates that investigation into the development of artificial intelligence systems to be applied for the benefit of the informal caregiver community is of merit.

This pilot study should be reproduced on a large scale. The amount of individual data gathered should be sufficient to render it big data, which could be examined from a spatial perspective. The geolocation of big data could produce maps showing the areas that most need interventions. The data generation and real-time analysis using an extended sample would also open up new possibilities for individual interventions. Big data would also be more useful for artificial intelligence applications. Artificial intelligence instruments such as Deep Neural Networks and machine learning could easily be integrated to get a more powerful digital tool. By constantly analysing the data flow, the information system could detect anomalous behaviour patterns in real-time and automatically send an alert to doctors or professionals. The system could send automatic ad-hoc advice to informal caregivers to help them maintain and improve their well-being, and so simultanouly the well-being of the greater community.

Another type of use involves the possibility of integrating the data collected by DDDs with biometrics through specific wearable devices (already used for digital health systems like Babylon; https:/www.babylonhealth.com/). This possibility would allow to gain another measure of the level of stress of caregivers and to know when an intervention is most needed.

\section{Conclusion}

This paper reports the findings of a pilot study aimed at testing the validity of a digital tool for instant reporting to measure the loss of well-being that mental illness causes to informal caregivers. The pilot study suggests that digital health tools can be useful to protect the community of caregivers. DDDs can assess the burden of disease and, in perspective, implemented with artificial intelligence, could be useful to offer efficient and cost-effective help to the community of informal caregivers.

Acknowledgements The paper has been built thanks to the development of the code for the digital app by Marco Scarselli. The research benefited from the preliminary work by Costanza Gasparo and Ester Macrì, members of the DataLifeLab of the University of Florence. The final writing of this paper benefited greatly from comments and suggestions of anonymous referees and of an editor of the International Journal of Community Well-Being.

Funding Open access funding provided by Università degli Studi di Firenze within the CRUI-CARE Agreement. The Florence Foundation Ente Cassa di Risparmio (CRF) financed the original pilot study.

Data Availability https://datalifelab.github.io/salute_mentale/.

\section{Compliance with Ethical Standards}

Code Availability https://github.com/datalifelab/salute_mentale?files=1 
Consent to Participate The research in this paper involved adults whose informed consent to participate was received, and all information anonymised.

Software License The developed source code was released under the MIT license according to Article 69 of the CAD (Digital Administration Code). Third parties interested in developing the project can freely use the software, available in open source.

\section{Appendix}

\section{Technical characteristics of the application}

The DDD created for the project is open source and all code has been released under the Massachusetts Institute of Technology. It follows the standards of the W3C and takes advantage of the properties of HTML5 so it can be used in almost all browsers in smartphones produced over the last 10 years. The notification system can integrate with leading push notification systems, hybrid applications, and instant messaging applications for maximum deployment. The main engine of the server-side application is the python FLASK web framework, standard in web-data-science-applications, highly scalable, and flexible. The released application enables the interaction of 60 users per second and data collection on a large scale. It is possible to follow about 3600 caregivers at a time. To monitor the development of the survey, the application enables the personalization of instant reports based on what the user (for instance, a researcher, a doctor, a social worker, a local health authority) wants to know. Collected data can be represented in both individual and group-aggregated forms. The instant reports are characterized by interactivity, i.e. they allow filtering variables to focus and gain detailed information on each specific time.

\section{An example of an instant report for monitoring available on the application: individual well-being}

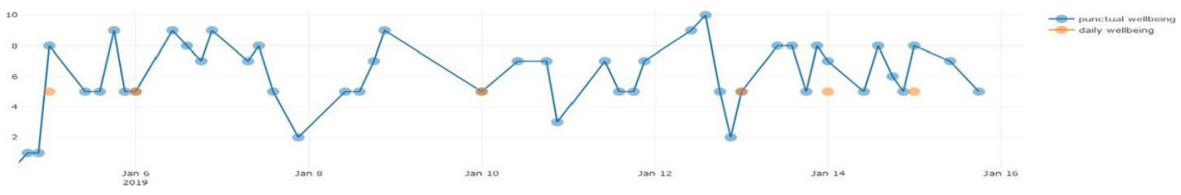

To optimise the user experience, all types of questions show adapted items and an optimized graphic design for mobile devices: for instance, the Likert scales are presented with a slider graphic element that is suitable for vertical monitors, such as those of smartphones. A dashboard for decision-makers was also structured. This tool also enables the analysis of data from a spatial perspective. Every answer given is accompanied by time and the geolocation of the participants. External independent factors may affect well-being: different degrees of urbanization, community aspects, and quality of services. Applied to a representative sample, this tool may serve to obtain maps that show areas most in need of intervention. The programming of the application is available in open data. 


\section{Geolocation of participants to the monitoring for decision-makers}

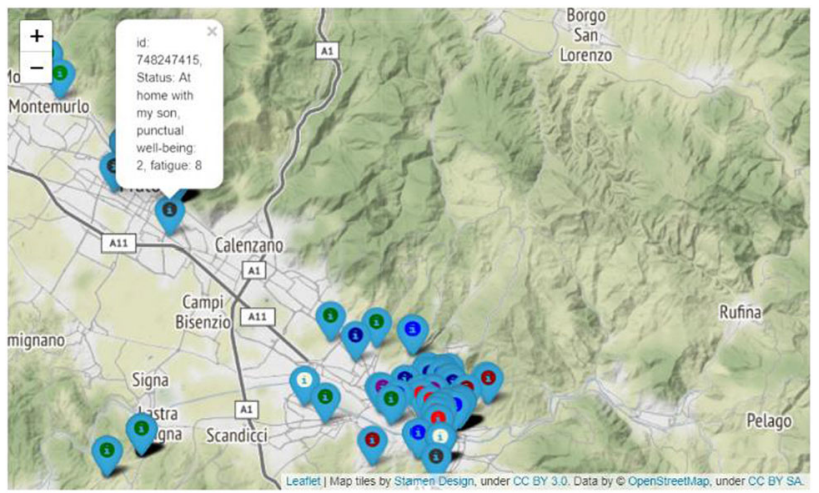

The programming developed for the digital app is available in open data at the GitHub.

Open Access This article is licensed under a Creative Commons Attribution 4.0 International License, which permits use, sharing, adaptation, distribution and reproduction in any medium or format, as long as you give appropriate credit to the original author(s) and the source, provide a link to the Creative Commons licence, and indicate if changes were made. The images or other third party material in this article are included in the article's Creative Commons licence, unless indicated otherwise in a credit line to the material. If material is not included in the article's Creative Commons licence and your intended use is not permitted by statutory regulation or exceeds the permitted use, you will need to obtain permission directly from the copyright holder. To view a copy of this licence, visit http://creativecommons.org/licenses/by/4.0/.

\section{References}

Ambikile, J. S., \& Outwater, A. (2012). Challenges of caring for children with mental disorders: Experiences and views of caregivers attending the outpatient clinic at Muhimbili National Hospital, Dar Es SalaamTanzania. Child and Adolescent Psychiatry and Mental Health, 6(1), 16.

Ampalam, P., Gunturu, S., \& Padma, V. (2012). A comparative study of caregiver burden in psychiatric illness and chronic medical illness. Indian Journal of Psychiatry, 54(3), 239-243.

Awad, A. G., \& Voruganti, L. N. P. (2008). The burden of schizophrenia on caregivers: A review. PharmacoEconomics, 26(2), 149-162.

Bastawrous, M. (2013). Caregiver burden. A critical discussion. International Journal of Nursing Studies, $50(3), 431-441$.

Bloom, D. E., Cafiero, E. T., Jané-Llopis, E., Abrahams-Gessel, S., Bloom, L. R., Fathima, S., ... \& Prettner, K. (2016). The global economic burden of noncommunicable diseases. Geneva: World Economic Forum; 2011. Available from: URL: http://www.hsph.harvard. edu/pgda/working.htm.

Daltro, M. C. D. S. L., Nunes, E. M., de Moraes, J. C., Montanari, P. M., Nobre, J. D. O. C., Marques, A. C. M. L., .. \& Marsiglia, R. G. (2016). Quality of life in caregivers of children and adolescents with mental disorders. International Archives of Medicine, 9. https://doi.org/10.1111/jcpp.12167

Diener, E., Lucas, R. E., \& Scollon, C. N. (2009). Beyond the hedonic treadmill: Revising the adaptation theory of well-being, In: The science of well-being (pp. 103-118). Dordrecht: Springer.

Doran, C. M., \& Kinchin, I. (2017). A review of the economic impact of mental illness. Australian Health Review, 43, 43-48. https://doi.org/10.1071/AH16115.

Dore, G., \& Romans, S. E. (2001). Impact of bipolar affective disorder on family and partners. Journal of Affective Disorders, 67(1-3), 147-158.

FDA. (2020) Digital Innovation Action Plan, https:/www.fda.gov/media/106331/download.

Goodrich, K., Kaambwa, B., \& Al-Janabi, H. (2012). The inclusion of informal care in applied economic evaluation: A review. Value in Health, 15(6), 975-981. 
Hoefman, R. J., van Exel, J., \& Brouwer, W. (2013). How to include informal care in economic evaluations. Pharmacoeconomics, 31(12), 1105-1119.

ISTAT (2014). 'I tempi della vita quotidiana', report sull'indagine Multiscopo 'Uso del tempo 2014'. https:// www.istat.it/it/files/2016/11/Report_Tempidivita_2014.pdf

Kaas, M. J., Lee, S., \& Peitzman, C. (2003). Barriers to collaboration between mental health professionals and families in the care of persons with serious mental illness. Issues in Mental Health Nursing, 24(8), 741756.

Krol, M., Papenburg, J., \& van Exel, J. (2015). Does including informal care in economic evaluations matter? A systematic review of inclusion and impact of informal care in cost-effectiveness studies. Pharmacoeconomics, 33(2), 123-135.

Litzelman, K., Tesauro, G., \& Ferrer, R. (2017). Internal resources among informal caregivers: Trajectories and associations with well-being. Quality of Life Research, 26(12), 3239-3250.

Ludwigs, K., Henning, L., \& Arends, L. R. (2019). Using the day reconstruction method-same results when used at the end of the day or on the next day? International Journal of Community Well-Being, 2(1), 6173.

Lynch, F. L., \& Dickerson, J. F. (2018). Societal costs of child and adolescent mental Health disorders (p. 136). The Oxford Handbook of Clinical Child and Adolescent Psychology.

Molebatsi, K., Ndetei, D. M., \& Opondo, P. R. (2017). Caregiver burden and correlates among caregivers of children and adolescents with psychiatric morbidity: A descriptive cross sectional study. Journal of Child \& Adolescent Mental Health, 29(2), 117-127.

Murphy, N. A., Christian, B., Caplin, D. A., \& Young, P. C. (2007). The health of caregivers for children with disabilities: Caregiver perspectives. Child: Care, Health and Development, 33(2), 180-187.

Musikanski, L., Rakova, B., Bradbury, J., Phillips, R., \& Manson, M. (2020). Artificial intelligence and community well-being: A proposal for an emerging area of research. International Journal of Community Well-Being, 1-17.

Novak, M., \& Guest, C. (1989). Application of a multidimensional caregiver burden inventory. The Gerontologist, 29(6), 798-803.

OECD Health Policy Studies. (2014). Making mental Health count: The social and economic costs of neglecting mental Health care. OECD Publishing.

OECD/European Union (2018), Health at a glance: Europe 2018: State of Health in the EU cycle, OECD Publishing, Paris/European Union, Brussels, https://doi.org/10.1787/health_glance_eur-2018-en.

Östman, M., \& Hansson, L. (2004). Appraisal of caregiving, burden and psychological distress in relatives of psychiatric inpatients. European Psychiatry, 19(7), 402-407.

Patel, V., Saxena, S., Lund, C., Thornicroft, G., Baingana, F., Bolton, P., et al. (2018). The lancet commission on global mental health and sustainable development. The Lancet, 392(10157), 1553-1598.

Pinquart, M., \& Sörensen, S. (2003). Differences between caregivers and non-caregivers in psychological health and physical health: A meta-analysis. Psychology and Aging, 18(2), 250-267.

Piotrowska, P. J., Tully, L. A., Lenroot, R., Kimonis, E., Hawes, D., Moul, C., Frick, P. J., Anderson, V., \& Dadds, M. R. (2017). Mothers, fathers, and parental systems: A conceptual model of parental engagement in programmes for child mental health - Connect, attend, participate, enact (CAPE). Clinical Child and Family Psychology Review, 20(2), 146-161.

Ritchie, H., \& Roser, M. (2020). Mental Health. Published online at OurWorldInData.org. Retrieved from: 'https://ourworldindata.org/mental-health' [online resource].

Tessler, R. C., \& Gamache, G. (2000). Family experiences with mental illness: Richard Tessler and Gail Gamache. USA: Greenwood Publishing Group.

Viana, M. C., Gruber, M. J., Shahly, V., Alhamzawi, A., Alonso, J., Andrade, L. H., Angermeyer, M. C., Benjet, C., Bruffaerts, R., Caldas-de-Almeida, J. M., Girolamo, G., Jonge, P., Ferry, F., Florescu, S., Gureje, O., Haro, J. M., Hinkov, H., Hu, C., Karam, E. G., Lépine, J. P., Levinson, D., Posada-Villa, J., Sampson, N. A., \& Kessler, R. C. (2013). Family burden related to mental and physical disorders in the world: Results from the WHO world mental Health (WMH) surveys. Revista Brasileira de Psiquiatria, 35, 115-125. https://doi.org/10.1590/1516-4446-2012-0919.

Vigo, D., Thornicroft, G., \& Atun, R. (2016). Estimating the true global burden of mental illness. The Lancet Psychiatry, 3(2), 171-178.

Vigo, D. V., Patel, V., Becker, A., Bloom, D., Yip, W., Raviola, G., ... \& Kleinman, A. (2019). A partnership for transforming mental health globally. The Lancet Psychiatry, (18)30434-6 https://doi.org/10.1016/ S2215-0366.

Weatherly, H., Faria, R., \& van den Berg, B. (2017). Quantifying informal care for economic evaluation in mental health. In Mental health economics (pp. 267-280). Cham: Springer. 
Whiteford, H. A., Degenhardt, L., Rehm, J., Baxter, A. J., Ferrari, A. J., Erskine, H. E., \& ...\& Vos, T. (2013). Global burden of disease attributable to mental and substance use disorders: Findings from the global burden of disease study 2010. The Lancet, 382(9904), 1575-1586.

WHO (2019). Mental disorders. https:/www.who.int/news-room/fact-sheets/detail/mental-disorders. Retrieved 01/05/2020.

WHO. (2020). Draft global strategy on digital health 2020-2024. https://www.who.int/docs/default-source/ documents/gs4dhdaa2a9f352b0445bafbc79ca799dce4d.pdf?sfvrsn=f1 12ede5_38. Retrived 15/07/2020.

Publisher's Note Springer Nature remains neutral with regard to jurisdictional claims in published maps and institutional affiliations. 